\title{
Metabolic Bone Disorder
}

National Cancer Institute

\section{Source}

National Cancer Institute. Metabolic Bone Disorder. NCI Thesaurus. Code C97045.

A group of disorders that affect the bones secondary to increased levels of minerals or deficient levels of minerals such as calcium, magnesium, phosphorus, and vitamin D. Representative examples are osteomalacia, osteoporosis, and Paget disease. 